\title{
Temperamental variation in learned irrelevance in humans
}

\author{
Aleksandra Gruszka ${ }^{1 \cdot B, C, D, E, F, G}$, Adrian M. Owen ${ }^{2 \cdot A}$ \\ 1: Institute of Psychology, Jagiellonian University, Cracow, Poland \\ 2: The Brain and Mind Institute, Western University, Natural Science Centre, London, Ontario, Canada
}

\section{BACKGROUND}

Learned irrelevance (LIRR) represents one of the mechanisms of attentional set-shifting and refers to the inability to attend to, or to learn about, any aspect of a stimulus previously experienced as irrelevant. Although it has been extensively studied in the context of clinical populations, not much is known about LIRR effects in relation to normal variation in individual differences. The present study was designed to assess how temperamental factors may modulate LIRR.

\section{PARTICIPANTS AND PROCEDURES}

Sixty-eight healthy volunteers performed a visual discrimination learning task modelled after Wisconsin Card Sorting Test. To test the susceptibility to learned irrelevance, participants were expected to shift their attention either to a dimension that prior to the extra-dimensional shift was completely irrelevant, or to a dimension that was previously partly correlated with reinforcement. Temperamental traits were assessed using the Formal Characteristics of Behaviour-Temperament Inventory (Zawadzki \& Strelau, 1997).
Intelligence level was stratified according to Raven's Advanced Progressive Matrices (Raven, Raven, \& Court, 2003).

\section{RESULTS}

Low level of Briskness and high level of Perseverance were related to enhanced susceptibility to LIRR. High levels of Activity and Emotional Reactivity were related to the poorer performance on the extra-dimensional set-shifting. No effects of other temperament characteristics or intelligence on LIRR were observed.

\section{CONCLUSIONS}

The results confirm a strong variation in LIRR related to individual differences in temperament, which appears to be unrelated to DA function. Our results highlight the importance of considering individual differences in studies on cognitive control.

\section{KEY WORDS}

temperament; learned irrelevance; attentional set-shifting; cognitive-flexibility

Corresponding Author - Aleksandra Gruszka, PhD, Institute of Psychology, Jagiellonian University, 6 Ingardena Str., 30-060 Cracow, Poland, e-mail: rusalka@apple.phils.uj.edu.pl

AUthors' CONTRibution - A: Study design - B: Data collection - C: Statistical analysis - D: Data interpretation .

E: Manuscript preparation · F: Literature search · G: Funds collection

to Cite this ARTiCle - Gruszka, A., \& Owen, A. M. (2015). Temperamental variation in learned irrelevance in humans.

Current Issues in Personality Psychology, 3(2), 94-104.

RECEIVED 19.05.2015 - REVIEWED 08.06.2015 - ACCEPTED 15.06.2015 - PUBLISHED 29.06.2015 


\section{BACKGROUND}

Learned irrelevance (LIRR) constitutes one of the mechanisms thought to be responsible for attentional set-shifting deficits, and refers to the inability to attend to, or to learn about, any aspect of stimulus, which has been previously experienced as irrelevant to a task at hand (Mackintosh, 1975). Evidence suggests that a wide variety of neurological and psychiatric conditions are related to altered susceptibility to LIRR. These include frontal lobe lesions (Owen, Roberts, Polkey, Sahakian, \& Robbins, 1991; Owen et al., 1993), idiopathic Parkinson's (PD) disease (Downes et al., 1989; Owen et al., 1993; Slabosz et al., 2006) and schizophrenia (Gray \& Snowden, 2005; Orosz, Feldon, Gal, Simon, \& Cattapan-Ludewig, 2008; Orosz et al., 2011). However, a paucity of data on normal variation in LIRR renders its interpretation amongst clinical studies, as well as generalization of the results, rather limited. Therefore, the present study was designed to assess the relationship between temperament and susceptibility to LIRR.

In the context of neuropsychological investigation LIRR is usually assessed using the intra- and extra-dimensional shifting (IDS and EDS, respectively) paradigm (Downes et al., 1989; Owen et al., 1992; Roberts, Robbins, \& Everitt, 1988) developed in the animal learning literature (Mackintosh, 1975). In discrimination learning tasks, an IDS occurs when a when a shift is required between two different values of the same dimension (e.g., from blue to red). Thus, an IDS represents lower-order flexibility. In contrast, an EDS represents higher-order flexibility, occurring when an attentional shift is required between two different perceptual dimensions, such as colour and shape (e.g. from "blue" to "squares" from the dimension "shape"). Impairments in neuropsychological or neurological populations are observed mainly when an EDS shift is required rather than IDS (Downes et al., 1989; Roberts et al., 1988). LIRR can be measured if, at the EDS stage of the task, the subject is required to shift his or her 'response set' to the stimulus dimension which was irrelevant to reinforcement prior to this stage of the test (Owen et al., 1993). This situation can be contrasted with the perseveration condition - in this case, the subject is required to disengage attention and shift it away from a dimension relevant prior to the EDS (Owen et al., 1993). The distinction between perseveration and LIRR plays an important role in the context of neuropsychology, since separate cognitive, neurochemical and possibly neuroanatomical mechanisms of LIRR and perseveration have been suggested (Gruszka, Hampshire \& Owen, 2010; Maes, Damen, \& Eling, 2004; Owen et al., 1993).

Some evidence has started to emerge that in normal population performance, an attentional set-shifting may actually be affected more by LIRR than per- severation (Maes et al., 2004; Maes, Vich, \& Eling, 2006). It has also been suggested that the relationship between cognitive flexibility and personality is dependent on dopamine (DA) function. According to Dreisbach and colleagues (Dreisbach, 2006; Dreisbach \& Goschke, 2004; Müller et al., 2007) individual differences in cognitive flexibility result from an interplay between stable maintenance of an attentional set (as reflected by perseveration) and a flexible switching (as reflected by LIRR), which impose antagonistic constraints on the cognitive control system. Accordingly, studies by Dreisbach (2006) and Müller (Müller et al., 2007) have shown that individuals characterised by higher DAergic activity exhibit greater cognitive-flexibility on the attentional set-shifting task, i.e., decreased perseveration and increased LIRR. Using the same paradigm Tharp and Pickering (2011) extended these finding by revealing that trait psychoticism (a major personality dimension consistently related to DA function; Lester, 1989) is associated (although not strongly) to a reverse pattern of effects. Relative to the low psychoticism, high psychoticism was correlated with greater switch costs in the perseveration condition and lower costs in the LIRR condition. Such studies are important because they can provide insights into the patterns of multiple brain systems underpinning traits.

The aim of the present study was to explore further the putative relationship between LIRR and temperament characteristics, as described in the Regulative Theory of Temperament (RTT) proposed by Strelau $(1983,1996)$. On the basis of their construct validity, at least several temperament dimensions postulated by the RTT are directly related to behavioural flexibility, making the theory highly relevant in the context of studies of individual differences in LIRR susceptibility. According to the RTT, temperament is a major structure that regulates the relationship between a person and his/her surroundings. By modulating the formal characteristics of behaviour, it helps to adjust the stimulative value of the environment and a person's own actions to the level consistent with their individual need for stimulation. The structure of temperament is constituted by two factors that regulate the temporal aspect of behaviour: briskness (BR) and perseveration (PE). Four additional factors, namely, sensory sensitivity (SS), emotional reactivity (ER), endurance (EN) and activity (AC), modulate the energetic aspect of behaviour.

In theory, by definition, at least two of the dimensions can be expected to be directly related to attentional set-shifting ability, i.e. BR and PE. BR is defined as 'a tendency to react quickly, to keep up a high tempo of performing activities, and to shift easily in response to changes in the surroundings from one behaviour (reaction) to another' (Strelau \& Zawadzki, 1995, p. 2). BR has three major components: mobility, speed and tempo. As Strelau and Za- 
wadzki (1993) explain, mobility is closely related to the construct of mobility proposed by Pavlov (as cited in Strelau \& Zawadzki, 1993), and the concept of adaptability proposed by Thomas and Chess (1977). The common denominator for mobility and adaptability is the ease with which behaviour is modified in response to changes in the environment. PE refers to 'a tendency to continue and to repeat behaviour after cessation of stimuli (situations) evoking this behaviour' (Strelau \& Zawadzki, 1995, p. 2). It has two major components: the tendency to repeat behaviour (recurrence) or to maintain it (persistence) after the extinction of the stimulus evoking it. These definitions suggest that both BR and PE (which, in fact, are moderately negatively correlated; Strelau \& Zawadzki, 1993) are linked to cognitive flexibility, and possibly to susceptibility to LIRR. These conclusions are party supported by a study by Ledzińska, Zajenkowski and Stolarski (2013) revealing that high BR and low PE are associated with smaller switch costs. However, this study utilised a paradigm (a dual test of divided and selective attention), which did not allow them to examine the relationship between BR or PE and susceptibility to LIRR.

Furthermore, as postulated by the RTT, ER denotes 'a tendency to react intensively to emotion-generating stimuli, expressed in high emotional sensitivity and in low emotional endurance' (Strelau \& Zawadzki, 1995, p. 2). As such, it has been shown to be related to symptoms of anxiety disorders (Strelau \& Zawadzki, 2011). Clinical neuropsychological studies imply that depression and anxiety disorders are associated with impairments in cognitive flexibility, i.e. impaired attentional set-shifting (Austin, Mitchell, \& Goodwin, 2001; Purcell, Maruff, Kyrios, \& Pantelis, 1997) and, in particular, EDS performance (Potter, McQuoid, Payne, Taylor, \& Steffens, 2012). Overall, the patterns observed for clinical populations are suggestive of the relationship between ER and higher-order flexibility.

In this study the relationship between attentional set-shifting and the abovementioned temperament factors was investigated by employing a visual discrimination learning task developed previously (Lewis, Slabosz, Robbins, Barker, \& Owen, 2005; Owen \& Slabosz, 2004; Slabosz et al., 2006). Our previous study provided evidence that the task can be used to assess higher-order flexibility and LIRR effect in healthy volunteers (Owen \& Slabosz, 2004). The task has also been shown to be sensitive to set-shifting impairments in patients with PD (Lewis et al., 2005; Slabosz et al., 2006). In the task the volunteers were required to learn a series of visual discriminations on the basis of feedback. At the EDS stage of the task, the participants were required to shift their attentional set to a dimension that had either been fully irrelevant, i.e. uncorrelated with reinforcement ('full irrelevance' condition) or partially reinforced, i.e. correlated with the reinforcement above the level of chance ('partial irrelevance' condition). This paradigm allows us to assess two aspects of attentional control: higherorder flexibility (as measured by the IDS/EDS manipulation) and susceptibility to LIRR (as measured by the 'full irrelevance/partial irrelevance' manipulation; see: Procedure). Although LIRR represents one of the mechanisms that might underlie difficulties in higher-order shifting, EDS deficits may also arise from several other types of endogenous control errors unrelated to stimulus pre-exposure effects i.e. failures in forming hypotheses concerning the new rule, inability to suppress the no-longer relevant task set and replace it by an appropriate new one, or deficient monitoring of performance (Ridderinkhof, Span, \& van der Molen, 2002).

On the basis of their behavioural characteristics as described above, it was expected that BR, PE and ER would modulate higher-level attentional flexibility, while BR and PE would also modulate susceptibility to LIRR. Accordingly, a high level of BR, low levels of PE and ER, respectively, were expected to be related to enhanced performance at the EDS stage of the task. Moreover, the high level of BR and the low level of PE were expected to be related to decreased sensitivity to LIRR. The results related to the two remaining RTT dimensions: AC and SS, as well as intelligence, were also analysed and reported for the sake of completeness, and to strengthen the possible conclusions relating LIRR specifically to some, but not other, aspects of temperament. AC denotes a tendency to either undertake behaviour of high stimulative value or to supply strong stimulation from the environment by means of behaviour (Strelau \& Zawadzki, 1993). SS refers to an "ability to respond to stimuli of low stimulative value" (Strelau \& Zawadzki, 1993, p. 327).

\section{PARTICIPANTS AND PROCEDURE}

\section{PARTICIPANTS}

Sixty-eight healthy college students participating in this experiment were recruited from the Institute of Psychology of Jagiellonian University in Krakow (mean age $M=20.100, \mathrm{SD}=1.450 ; 14$ male, at least 12 years of formal education). Permission for the study was obtained from the local research ethics committee and all subjects granted consent for their participation.

\section{PROCEDURE}

The Formal Characteristics of Behaviour-Temperament Inventory (FCB-TI) (Strelau \& Zawadzki, 1993; Zawadzki \& Strelau, 1997) was used to stratify a sample according to a level of SS, EN, ER, AC, 
BR and PE. The FCB-TI has satisfactory psychometric characteristics and its scales are replicable across samples (Strelau \& Zawadzki, 1995).

Raven's Advanced Progressive Matrices (RAPM) (Raven et al., 2003) was also administered in order to control for the relationship between intelligence and attentional performance (e.g., Hunt \& Lansman, 1982; Nęcka, 2000).

Learned Irrelevance task. The visual discrimination test used in this study was modelled on the perseveration and learned irrelevance test proposed by Owen (Owen et al., 1993) as a refined version of the CANTAB ID/ED set-shifting task (Owen et al., 1992).

In the current task the volunteers were required to learn a series of visual discriminations on the basis of feedback provided automatically by the computer after each trial (see Figure 1). The test consisted of eight stages. It began with a simple discrimination and reversal for stimuli varying in only one dimension (i.e. colour). Two additional dimensions were then introduced (the shape and number of items), and compound discrimination and reversal were tested. At the IDS stage and reversal, new exemplars from each of the three dimensions were presented, requiring the subjects to transfer the previously learnt rule to a novel set of exemplars of the same dimension (i.e. colour). Finally, at the EDS and reversal, novel exemplars from each of the three dimensions were introduced again, and the subjects had to shift ,response set' to one of the alternative stimulus dimensions which had been previously irrelevant (either the shape or the number of elements).

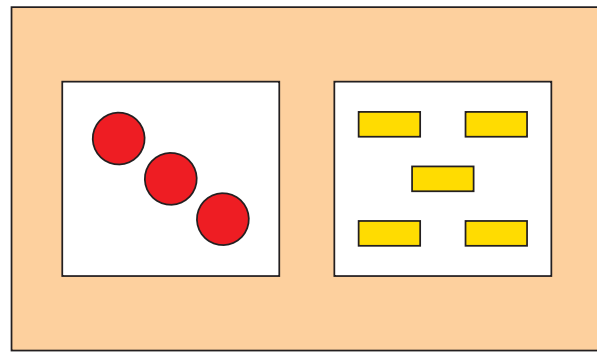

Colour relevant (red)

Shape partly relevant $(+75 \%$ circle $)$

Number fully irrelevant

IDS

Shift from red to green required

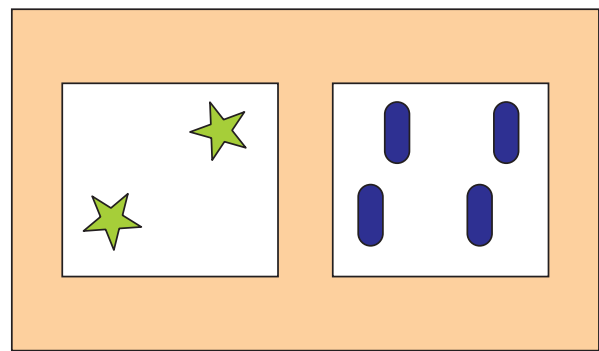

Colour relevant (green)

Shape partly relevant $(+75 \%$ star $)$

Number fully irrelevant

EDS

Shift from red to triangle required

'Partial relevance' condition

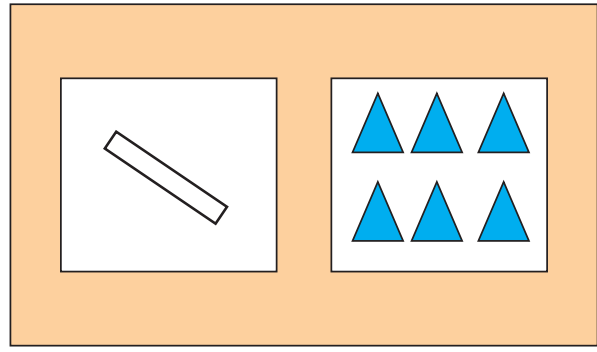

Colour irrelevant

Shape relevant (triangle)

Number irrelevant
Shift from red to one item required 'Full irrelevance' condition

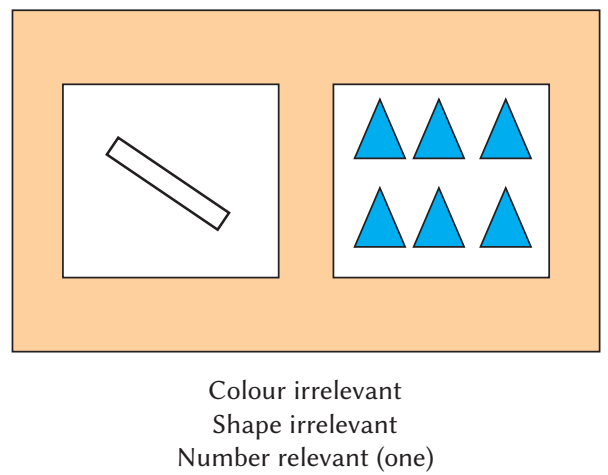

Figure 1. Learned irrelevance: Summary of the procedure for the intra-dimensional shift (IDS) and extradimensional shift (EDS) stages of the learned irrelevance task. Stimuli shown are for example only (adopted from Slabosz et al., 2006). 
To assess the susceptibility to LIRR, at the EDS stage of the task the participants were required to shift attentional set from colour to another stimulus dimension (shape or number) which has been previously (prior to the EDS) either fully irrelevant or partially reinforced. In the case of the fully irrelevant dimension, any given value of this dimension (e.g. square or circle) randomly co-occurred with the reinforced value of the currently relevant dimension (i.e. blue or red). In other words, the fully irrelevant dimension was reinforced randomly, and in this sense was equivalent to the irrelevant dimension of the original task proposed by Owen (Owen et al., 1993). By contrast, in case of the partially relevant dimension, one value of this dimension co-occurred with the reinforced value of the currently relevant dimension in $75 \%$ of trials preceding the EDS. As a result, the partially relevant dimension predicted the reinforcement at a level that was greater than chance. The 'full/partial irrelevance' procedure allowed us to prevent a contaminating effect of novelty of the EDS target dimension on LIRR (Daffner et al., 2000; Maes et al., 2006). The results of our previous studies have confirmed that LIRR is dependent on the level of irrelevance of a given dimension prior to an EDS (Lewis et al., 2005; Owen \& Slabosz, 2004; Slabosz et al., 2006).

During each trial, the volunteers responded by pressing one of two response keys corresponding to whether the chosen stimulus was on the left or right side of the screen. Feedback was provided after each trial. The criterion for passing from the previous to the next stage was that of 12 consecutive correct responses, and failure to achieve this criterion within 100 trials resulted in the premature discontinuation of the test. Every volunteer was randomly assigned

Table 1

The mean scores, standard deviations and standard errors in the FCB-TI scales and the RAMP as obtained in the current study

\begin{tabular}{cccc}
\hline & Mean & $\begin{array}{r}\text { Standard } \\
\text { deviation }\end{array}$ & $\begin{array}{c}\text { Standard } \\
\text { error }\end{array}$ \\
\hline BR & 6.206 & 3.919 & 0.475 \\
PE & 8.761 & 2.444 & 0.299 \\
SS & 2.910 & 2.308 & 0.282 \\
ER & 8.515 & 4.517 & 0.548 \\
EN & 11.941 & 4.756 & 0.577 \\
AC & 8.403 & 4.540 & 0.555 \\
IQ & 24.854 & 5.596 & 0.808 \\
\hline
\end{tabular}

Note. BR - briskness (FCB-TI), PE - perseveration (FCB-TI) $\mathrm{SS}$ - sensory sensitivity (FCB-TI), ER - emotional reactivity (FCB-TI), EN - endurance (FCB-TI), AC - activity (FCB-TI), $\mathrm{IQ}$ - inelligence (RAMP) to one of the test conditions: 'full irrelevance' or 'partial irrelevance', and was required to shift 'response set' from colour to either shape or to number. The EDS target dimensions (shape or number) were counterbalanced across the test conditions. However, to make sure that conditions preceding the EDS were identical across task conditions and did not differentially affect ED shifting, only colour was used as the dimension relevant prior to the EDS.

\section{RESULTS}

Errors to criterion were analysed at the IDS and the EDS stages of the test. Early stages were not analysed, since in these preliminary (preshift) trials, all of the conditions were formally identical. To assess the relationship between shift (IDS, EDS; within-subject factor), the test condition ('full irrelevance', 'partial relevance'; between-subject factor) and the EDS target dimension (shape, number; between-subject factor) a repeated measures three-way analysis of variance procedure was employed. Although the primary hypothesis concerned the two-way interaction between the shift and the test condition factors, the effects of the EDS target dimension was also assessed to explore the possibility that the salience of that dimension might affect EDS performance.

In order to assess the influence of individual differences on the LIRR performance, median splits were completed on the sample, on the basis of temperament scores for SS, EN, ER, AC, BR and PE, as well as intelligence. Table 1 provides the results of descriptive statistics for the FCB-TI scales and the RAMP scores obtained in the current study.

In an attempt to replicate our previous findings, the three-way analysis of variance of shift (IDS vs. EDS), the test condition ('full irrelevance' vs. 'partial irrelevance') and EDS target dimension factors was performed. It revealed a highly significant main effect of shift $(F(1,64)=39.778, p<.0001, \eta=.383)$, with more errors being committed at the EDS compared to the IDS stage. It also revealed a significant main effect of the test condition $(F(1,64)=11.501$, $p=.001, \eta=.152$ ), with more errors being committed under the 'full irrelevance' condition, as compared to the 'partial relevance' condition. The main effect of the target dimension was also significant $(F(1,64)=4.184$, $p=.031, \eta=.069)$ revealing that shifting to shape was easier than shifting to the number of elements. Furthermore, the interaction between shift and the test condition was also significant $(F(1,64)=10.225$, $p=.002, \eta=.138$ ), reflecting the fact that EDS was more difficult under the fully irrelevant condition compared to the partially irrelevant condition (see Figure 2). Finally, the interaction between shift and EDS target dimension was significant as well $(F(1,64)=6.154$, $p=.016, \eta=.087)$, mirroring the fact that shifting 
to number was more difficult than shifting to shape. However, the three-way interaction of shift, the test condition and EDS target dimension was not significant $(F(1,64)=0.4261)$, suggesting that although shape was a more salient dimension than number, there was no difference in the overall pattern of EDS shifting to shape compared to EDS shifting to number.

To analyse the effects of BR on the task performance, a three-way ANOVA of BR (low, high), shift (IDS, EDS) and the test condition ('full irrelevance', 'partial irrelevance') was performed. The analysis revealed no significant effect of BR $(F(1,64)=2.004)$ and no interaction between BR and shift $(F(1,64)=2.167)$. However, the analysis revealed a significant 2-way interactions between $\mathrm{BR}$ and the test condition $(F(1,64)=9.074, p=.004, \eta=.108)$ and a significant 3-way interaction between the BR, shift and the test condition $(F(1,64)=8.438, p=.005, \eta=.116)$. These results showed an interesting pattern according to which the subjects scoring high on the BR scale appear to be not affected by the 'full/partial irrelevance' manipulation, but the subjects scoring low on BR scale are highly susceptible to LIRR (Figure 3).

A three-way ANOVA of PE (low, high), shift (IDS, EDS) and the test condition ('full irrelevance', 'partial irrelevance') revealed neither a significant effect of PE $(F(1,64)=1.392)$ nor an interaction between PE and shift $(F(1,64)=1.297)$. However, it revealed a significant 2-way interaction between $\mathrm{PE}$ and the test condition $(F(1,64)=4.316, p=.042$, $\eta=.064$ ) and a significant 3-way interaction between $\mathrm{PE}$, shift and the test condition $(F(1,64)=4.038$,

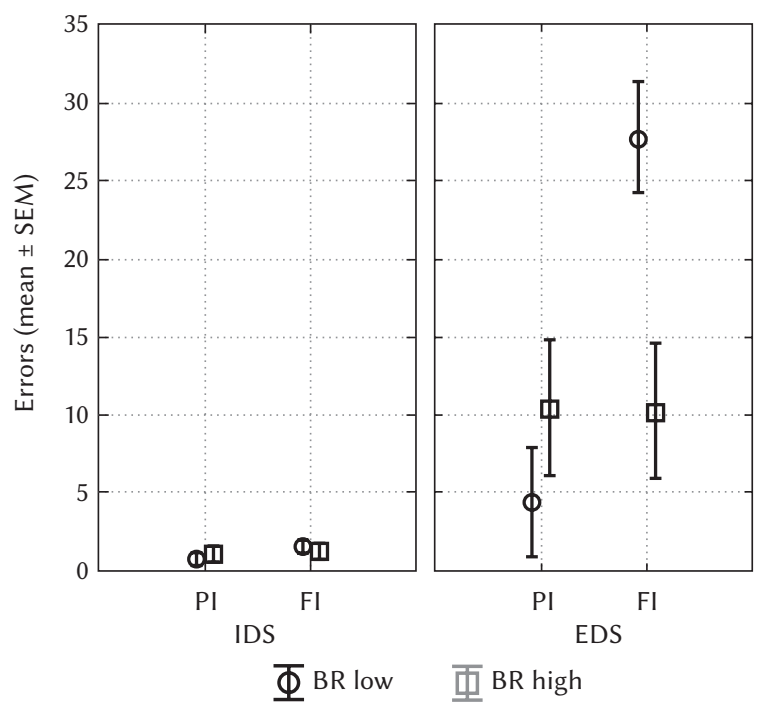

Figure 3. Effect of BR on error rate in the learned irrelevance task. The mean number of errors for the participants scoring low and high on the BR scale are shown for both the intradimensional shift (IDS) and extradimensional shift (EDS) in the 'partial irrelevance' (PI) and 'full irrelevance' (FI) conditions. Bars represent standard error of the mean. $p<.05, \eta=.060)$. Taken together these results suggest that high PE is related to an elevated susceptibility to LIRR (Figure 4).

A three-way ANOVA of ER (low, high), shift (IDS, EDS) and the test condition ('full irrelevance', 'partial irrelevance') revealed the significant main effect of this factor $(F(1,64)=4.029, p=.049, \eta=.059)$. Fur-

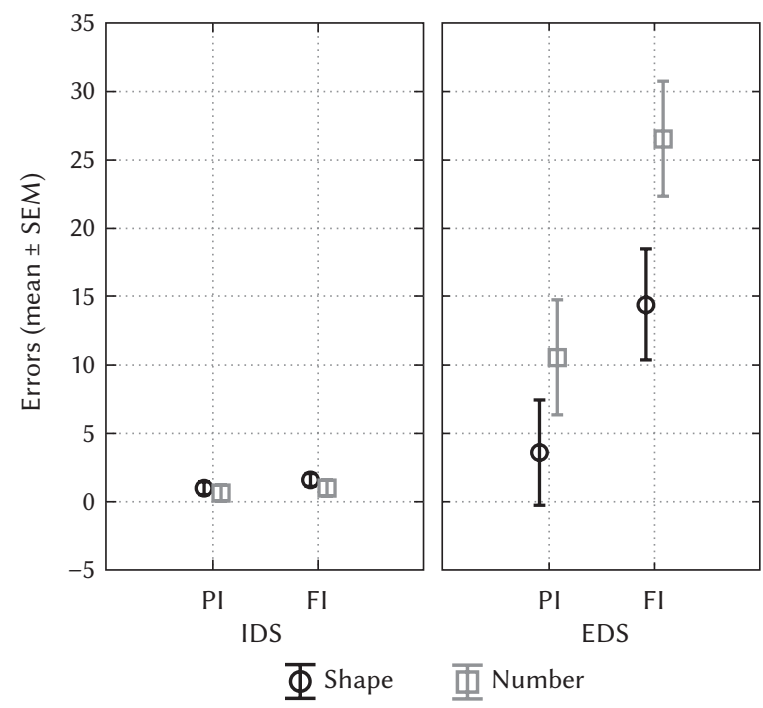

Figure 2. Effect of irrelevance of a dimension on set-shifting performance and mean errors to criterion in relation to shift (intra-dimensional shift, IDS and extra-dimensional shift, EDS) and test condition factors ('partial irrelevance', PI and 'full irrelevance', FI). Bars represent standard error of the mean.

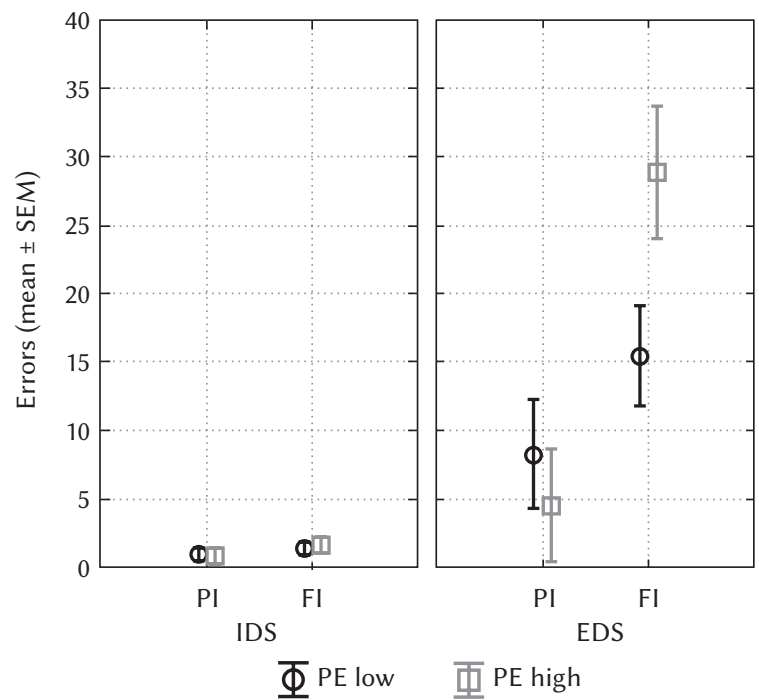

Figure 4. Effect of PE on error rate in the learned irrelevance task. The mean number of errors for the participants scoring low and high on the PE scale are shown for both the intradimensional shift (IDS) and extradimensional shift (EDS) in the "partial irrelevance' (PI) and 'full irrelevance' ( $\mathrm{FI}$ ) conditions. Bars represent standard error of the mean. 
thermore, it revealed a significant 2-way interaction between ER and shift $(F(1,64)=4.416, p=.039$, $\eta=.064$ ) suggesting that in comparison to the low-scoring participants, the subjects scoring high on this temperamental dimension committed more errors at the EDS stage of the task. Neither the 2-way interaction of ER and the test condition $(F(1,64)=0.923)$, nor the 3-way interaction of ER, shift and the test condition $(F(1,64)=1.388)$ appeared significant (Figure 5).

A three-way ANOVA of AC (low, high), shift (IDS, EDS) and the test condition ('full irrelevance', 'partial relevance') revealed a significant main effect of AC $(F(1,64)=6.527, p=.013, \eta=.093)$. It also revealed a significant 2-way interaction between $\mathrm{AC}$ and the test condition $(F(1,64)=4.646, p=.035, \eta=.068)$, a significant 2-way interaction between $\mathrm{AC}$ and shift $(F(1,64)=6.164, p=.016, \eta=.089)$. At the same time, a 3-way interaction between $\mathrm{AC}$, shift and the test condition was insignificant $(F(1,64)=3.318)$. These results suggest that participants scoring high on AC, as compared to those scoring low, committed fewer EDS errors, and fewer errors under 'full irrelevance' condition (Figure 6).

Finally, no significant main effects nor interactions were observed for SS, EN and intelligence in the respective analyses. Moreover, as expected from the analyses of the main task effects, the effects of shift, the test condition, and the 2-way interaction of shift and the test condition, were confirmed to be significant by all the respective differential analyses.

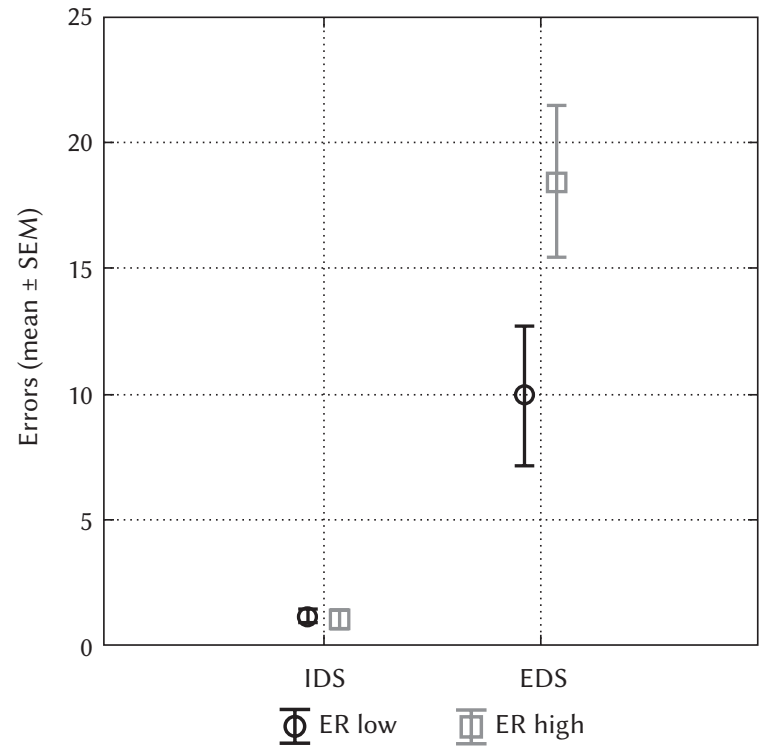

Figure 5. Effect of ER on error rate in the learned irrelevance task. The mean number of errors for the participants scoring low and high on the ER scale are shown for the intradimensional shift (IDS) and extradimensional shift (EDS). Bars represent standard error of the mean.

\section{DISCUSSION}

The results of the current study contribute to the literature by providing insights concerning temperament variation in higher-order flexibility and LIRR susceptibility. The main finding here is that, as expected on the basis of their behavioural characteristics, traits modulating temporal aspects of behaviour - BR and PE - are related to susceptibility to LIRR. Although it was hypothesised that BR and PE would also be linked to higher-order flexibility, it seems that in these cases set-shifting capacity is primary and strongly modulated by stimulus preexposure effects (and not other general factors contributing to higher-order flexibility; Ridderinkhof et al., 2002). As a result, in the case of $\mathrm{BR}$ and $\mathrm{PE}$, LIRR seems to be the only factor accounting for EDS-related variance. Furthermore, the analysis revealed that $\mathrm{ER}$ and $\mathrm{AC}$ are related to higher-order flexibility, whilst AC is also related to LIRR. To our knowledge, apart from the preliminary data on LIRR and psychoticism presented by Tharp and colleagues (Tharp \& Pickering, 2011), this is the first study to reveal such strong effects of temperament on LIRR.

The striking similarity of the cognitive patterns for BR, PE, ER and AC may be partly accounted for by the fact that the RTT traits are not orthogonal to each other (Strelau \& Zawadzki, 1993). Thus, PE and ER are strongly positively correlated, whilst low to moderate negative correlations link $\mathrm{PE}$ to $\mathrm{AC}$ and $\mathrm{BR}$, respectively. Furthermore, correlational analyses between FBT-CI and Pavlovian Temperament Survey

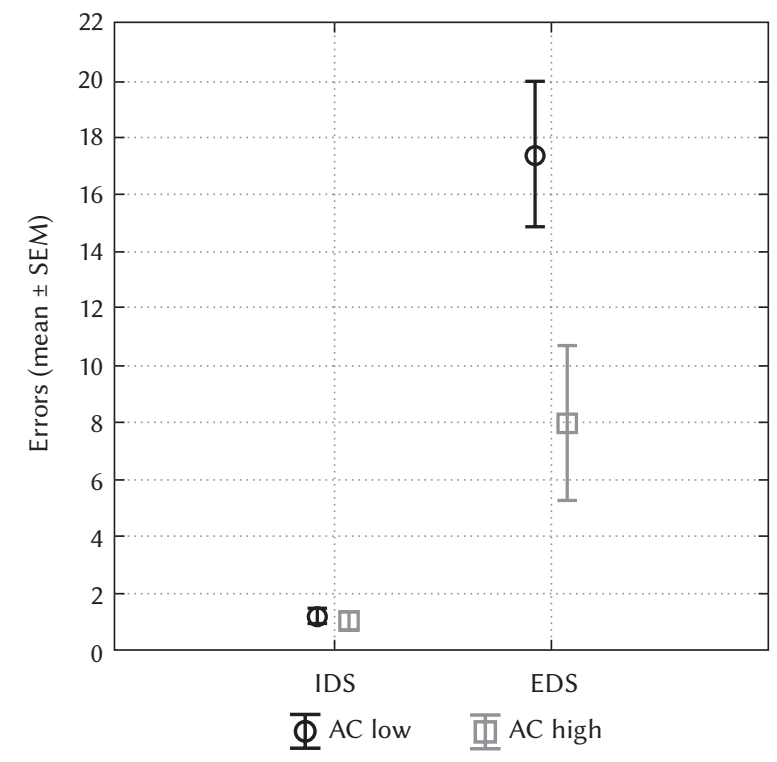

Figure 6. Effect of $\mathrm{AC}$ on error rate in the learned irrelevance task. The mean number of errors for the participants scoring low and high on the AC scale are shown for the intradimensional shift (IDS) and extradimensional shift (EDS). Bars represent standard error of the mean. 
factors (PTS; see Strelau, Angleitner, \& Bantelmann, 1990), as well as The Revised Dimensions of Temperament Survey factors (DOTS-R; Windle \& Lerner, 1986) have revealed that the patterns are very consistent across some of the measures (Strelau \& Zawadz$\mathrm{ki}, 1995)$. All of the traits under discussion are moderately correlated with mobility (as measured by PTS), although the correlations for BR and AC are positive, whilst those for PE and ER are negative. The four traits exhibit also an analogous pattern of correlations with Flexibility-Rigidity factor (F-R; DOTS-R), which is similar to mobility (PTS). Thus, BR, PE, ER and $\mathrm{AC}$ are all related to adaptive skills: whereas $\mathrm{BR}$ and $\mathrm{AC}$ are linked to high adaptive skills, this pattern is reversed for $\mathrm{PE}$ and $\mathrm{ER}$.

Furthermore, the idea of antagonistic demands imposed on cognitive control by the set-maintaining and set-shifting proposed by Dreisbach and colleagues (Dreisbach, 2006; Dreisbach \& Goschke, 2004; Müller et al., 2007) is suggestive of the notion that adaptive behaviour may depend not only upon mobility, but also upon resistance to distraction. Within psychometric approach these two aspects are represented in DOTS-R by two factors: F-R (described above) and Low Distractibility (DIS). Individuals scoring high on this scale tend to be able to concentrate and maintain perceptual focus despite extraneous stimulation (Windle \& Lerner, 1986). In line with this reasoning, BR, PE, ER (but not AC) are mildly correlated with DIS (Strelau \& Zawadzki, 1995). Thus, positive correlation observed for DIS and BR imply that high BR is related to the ability to resist distraction, whereas negative correlations for DIS and PE or ER, respectively, suggest otherwise.

In sum, the relationships between mobility and ER or AC, respectively, are congruent with the current observation that the traits are related to higherorder flexibility. Furthermore, the relationship between DIS and BR or PE, respectively, may further explain the observed link between these traits and susceptibility to LIRR. It remains an open question as to why ER - which seems so similar to PE in terms of mobility, F-R and DIS - did not exhibit a relationship to LIRR. It is also of interest why AC is not related to distractibility, but yet interacts with LIRR. Overall, the current results concerning the relationships between higher-order flexibility, susceptibility to LIRR and the RTT traits highlight the importance of individual differences in cognitive control.

The second important implication of the current study is that individual differences in LIRR are not necessary mediated by the DA function, as postulated by Dreisbach and colleagues (Dreisbach, 2006; Dreisbach et al., 2005; Müller et al., 2007). Our previous studies (Lewis et al., 2005; Slabosz et al., 2006) have documented that shifting costs captured by the LIRR manipulation of the current task are not mediated by DA levels. Slabosz and colleagues (2006) have tested patients with PD on and off L-dopa, as well as healthy control participants on the LIRR task used here, and a working memory task. The patients made more errors than control participants in the 'full irrelevance' condition, but not in the 'partial irrelevance' condition. More importantly, L-dopa had no effect on the patients' EDS performance, despite improving their working memory. These results confirm that LIRR deficit in PD, unlike other executive impairments in this group, is relatively insensitive to the central dopaminergic dysfunction present in this condition.

At first glance, the conclusion that LIRR variability in the normal population in independent on DA function is in disagreement with the recent findings. As noted before, Dreisbach and colleagues findings (Dreisbach et al., 2005; Müller et al., 2007) have demonstrated that greater DAergic activity is linked to decreased switch costs on the perseveration condition, and to increased costs on the LIRR condition (see also Tharp and Pickering, 2011). However, the paradigm used in the series of studies by Dreisbach, Müller, Tharp and colleagues differed from ours in one important way. In our case LIRR did not pertain to specific values of the same dimension, but instead to a higher order rule, whilst in the paradigm used by Dreisbach and others, LIRR was assessed on the basis of continued response to the same stimulus dimension (i.e., after the switch the former distracter colour became the target colour, and the new colour became the distracter colour). In paradigms modelled after CANTAB IDS/EDS task the latter type of switching reflects actually intra-dimensional reversal shifting (i.e., switching attention away from a previous target to a previous non-target following a change in reward contingency). It has been demonstrated that levodopa impairs reversal learning in PD (Cools, Barker, Sahakian, \& Robbins, 2001), suggesting that this process is dependent on DA levels (but see also Clarke, Walker, Dalley, Robbins, \& Roberts, 2006; Williams-Gray, Hampshire, Barker, \& Owen, 2008; for opposite conclusion). Overall, we believe that the variability of the findings reported is likely to reflect differences in task demands. LIRR, as operationalised in the current paradigm, is not dependent on DA function.

Furthermore, the current research adds to the literature on temperament as well, by supporting the construct validity of the RTT traits. Although the functional significance of temperament, especially under high demands, is well established (e.g., Strelau \& Klonowicz, 2006; Strelau \& Zawadzki, 2005; Zawadzki \& Popiel, 2012), less is known about its relationship to more molecular processes (Strelau, 1991). The results of the current study help to fill this gap.

Moreover, studies on individual differences in cognitive control, as represented by the current investigation, are also essential in order to gain a more complete understanding of brain systems involved in temper- 
ament/personality traits. Thus, one may expect that the current study allows us to draw some conclusions regarding the biological basis of the RTT traits under investigation. Nevertheless, it would be premature to make strong predictions concerning the neurochemical basis of the RTT traits on the basis of the current results. Although their biological bases are strong (as indicated by genetic studies, on average $46 \%$ of their variance can be explained by genetic factors; see Strelau, 1996), these mechanisms have not been specified in terms of the neurochemical and neuroanatomical systems involved. Within the RTT framework, the formal characteristics of behaviour are seen as originating from an interaction between all mechanisms, constituting an individual configuration of neurological and endocrine mechanisms that regulate behaviour, i.e., so-called neurohormonal individuality (Strelau, 1983). In other words, as yet the RTT traits have not been linked to specific biological mechanisms.

The limitations of the current study concern mainly two aspects. First of all, the character of the study is exploratory. Based on their content validity, the relationship between $\mathrm{BR}, \mathrm{PE}, \mathrm{ER}$ and even perhaps $\mathrm{AC}$ and cognitive flexibility seems predictable. The obtained findings are, however, difficult to interpret in terms of underlying mechanisms, because of the paucity of published data suitable as a reference. Moreover, it would be useful to include a larger sample of subjects in a future study, as present analysis suggests the potential link between LIRR and ER.

In summary, our results confirm a strong variation in LIRR related to individual differences in temperament, which appears to be not affected by DA function. It indicates that inclusion of individual differences into neuroscientific research on cognitive control may help to understand such processes, for example, by helping to account for the observed variation. It has been suggested that the LIRR paradigm, in particular, might serve as a translational model for (pre)attentive information processing deficits in schizophrenia (Klinkenberg, Blokland, Riedel, \& Sambeth, 2012). Knowledge of individual variation related to LIRR may add to the refinement of these types of models. Furthermore, the current research adds to the literature by supporting the construct validity of the RTT traits. It also suggests that further research aiming at understanding temperament-related variation in cognitive stability-distractibility would be valuable.

This work was supported by grant N106 042434 from the the National Committee of Science to A.G.

\section{REFERENCES}

Austin, M. P., Mitchell, P., \& Goodwin, G. M. (2001). Cognitive deficits in depression: possible implications for functional neuropathology. The British
Journal of Psychiatry: The Journal of Mental Science, 178, 200-206.

Clarke, H., Walker, S., Dalley, J., Robbins, T., \& Roberts, A. (2006). Cognitive Inflexibility after Prefrontal Serotonin Depletion Is Behaviorally and Neurochemically Specific. Cerebral Cortex, 17, 18-27.

Cools, R., Barker, R. A., Sahakian, B. J., \& Robbins, T. W. (2001). Enhanced or Impaired Cognitive Function in Parkinson's Disease as a Function of Dopaminergic Medication and Task Demands. Cerebral Cortex, 11, 1136-1143.

Daffner, K. R., Mesulam, M. M., Scinto, L. F. M., Acar, D., Calvo, V., Faust, R., \& Holcomb, P. (2000). The central role of the prefrontal cortex in directing attention to novel events. Brain, 123, 927-939.

Downes, J. J., Roberts, A. C., Sahakian, B. J., Evenden, J. L., Morris, R. G., \& Robbins, T. W. (1989). Impaired extra-dimensional shift performance in medicated and unmedicated Parkinson's disease: Evidence for a specific attentional dysfunction. Neuropsychologia, 27, 1329-1343.

Dreisbach, G. (2006). How positive affect modulates cognitive control: The costs and benefits of reduced maintenance capability. Brain and Cognition, 60, 11-19.

Dreisbach, G., \& Goschke, T. (2004). How Positive Affect Modulates Cognitive Control: Reduced Perseveration at the Cost of Increased Distractibility. Journal of Experimental Psychology: Learning, Memory, and Cognition, 30, 343-353.

Dreisbach, G., Müller, J., Goschke, T., Strobel, A., Schulze, K., Lesch, K.-P., \& Brocke, B. (2005). Dopamine and Cognitive Control: The Influence of Spontaneous Eyeblink Rate and Dopamine Gene Polymorphisms on Perseveration and Distractibility. Behavioral Neuroscience, 119, 483-490.

Gray, N. S., \& Snowden, R. J. (2005). The relevance of irrelevance to schizophrenia. Neuroscience and Biobehavioral Reviews, 29, 989-999.

Gruszka, A., Hampshire, A., \& Owen, A. M. (2010). Learned Irrelevance Revisited: Pathology-Based Individual Differences, Normal Variation and Neural Correlates. In: A. Gruszka, G. Matthews, \& B. Szymura (eds.). Handbook of Individual Differences in Cognition (pp. 127-144). New York, NY: Springer New York.

Hunt, E. B., \& Lansman, M. (1982). Individual differences in attention. In: R. J. Sternberg (ed.). Advances in the psychology of human intelligence (Vol. 1, pp. 207-254). Hillsdale, NJ: Lawrence Erlbaum Associates.

Klinkenberg, I., Blokland, A., Riedel, W., \& Sambeth, A. (2012). Human electrophysiological correlates of learned irrelevance: effects of the muscarinic M1 antagonist biperiden. The International Journal of Neuropsychopharmacology, 15, 1375-1385.

Ledzińska, M., Zajenkowski, M., \& Stolarski, M. (2013). Temperament i poznanie: energetyczne i czasowe 
zaplecze umystu [Temperament and cognition]. Warszawa: Wydawnictwo Naukowe Scholar.

Lester, D. (1989). A neurotransmitter basis for Eysenck's theory of personality. Psychological Reports, 64, 189-190.

Lewis, S. J. G., Slabosz, A., Robbins, T. W., Barker, R. A., \& Owen, A. M. (2005). Dopaminergic basis for deficits in working memory but not attentional set-shifting in Parkinson's disease. Neuropsychologia, 43, 823-832.

Mackintosh, N. J. (1975). A Theory of Attention: Variations in the Associability of Stimuli with Reinforcement. Psychological Review, 82, 276-298.

Maes, J. H. R., Damen, M. D. C., \& Eling, P. A. T. M. (2004). More learned irrelevance than perseveration errors in rule shifting in healthy subjects. Brain and Cognition, 54, 201-211.

Maes, J. H. R., Vich, J., \& Eling, P. A. T. M. (2006). Learned irrelevance and response perseveration in a total change dimensional shift task. Brain and Cognition, 62, 74-79.

Müller, J., Dreisbach, G., Goschke, T., Hensch, T., Lesch, K.-P., \& Brocke, B. (2007). Dopamine and cognitive control: the prospect of monetary gains influences the balance between flexibility and stability in a set-shifting paradigm. The European Journal of Neuroscience, 26, 3661-3668.

Nęcka, E. (2000). Pobudzenie intelektu: zarys formalnej teorii inteligencji [The Formal Theory of Intelligence]. Kraków: Universitas.

Orosz, A. T., Feldon, J., Gal, G., Simon, A. E., \& Cattapan-Ludewig, K. (2008). Deficient associative learning in drug-naive first-episode schizophrenia: Results obtained using a new visual within-subjects learned irrelevance paradigm. Behavioural Brain Research, 193, 101-107.

Orosz, A. T., Feldon, J., Simon, A. E., Hilti, L. M., Gruber, K., Yee, B. K., \& Cattapan-Ludewig, K. (2011). Learned Irrelevance and Associative Learning Is Attenuated in Individuals at Risk for Psychosis but not in Asymptomatic First-Degree Relatives of Schizophrenia Patients: Translational State Markers of Psychosis? Schizophrenia Bulletin, 37, 973-981.

Owen, A. M., James, M., Leigh, P. N., Summers, B. A., Marsden, C. D., Quinn, N. P., \& Robbins, T. W. (1992). Fronto-striatal cognitive deficits at different stages of Parkinson's diesease. Brain, 115, 1727-1751.

Owen, A. M., Roberts, A. C., Hodges, J. R., Summers, B. A., Polkey, C. E., \& Robbins, T. W. (1993). Contrasting mechanisms of impaired attentional set-shifting in patients with frontal lobe damage or Parkinson's disease. Brain: A Journal of Neurology, 116 (Pt 5), 1159-1175.

Owen, A. M., Roberts, A. C., Polkey, C. E., Sahakian, B. J., \& Robbins, T. W. (1991). Extra-dimensional versus intra-dimensional set shifting performance following frontal lobe excisions, temporal lobe excisions or amygdalo-hippocampectomy in man. Neuropsychologia, 29, 993-1006.

Owen, A. M., \& Slabosz, A. (2004). Mechanizm przerzutności uwagi - wyuczona nieadekwatność. Studia Psychologiczne, 42, 71-77.

Potter, G. G., McQuoid, D. R., Payne, M. E., Taylor, W. D., \& Steffens, D. C. (2012). Association of attentional shift and reversal learning to functional deficits in geriatric depression. International Journal of Geriatric Psychiatry, 27, 1172-1179.

Purcell, R., Maruff, P., Kyrios, M., \& Pantelis, C. (1997). Neuropsychological function in young patients with unipolar major depression. Psychological Medicine, 27, 1277-1285.

Raven, J., Raven, J. C., \& Court, J. H. (2003). Manual for Raven's Progressive Matrices and Vocabulary Scales. Section 1: General Overview. San Antonio, TX: Harcourt Assessment.

Ridderinkhof, K. R., Span, M. M., \& van der Molen, M. W. (2002). Perseverative Behavior and Adaptive Control in Older Adults: Performance Monitoring, Rule Induction, and Set Shifting. Brain and Cognition, 49, 382-401.

Roberts, A. C., Robbins, T. W., \& Everitt, B. J. (1988). The effects of intradimensional and extradimensional shifts on visual discrimination learning in humans and non-human primates. The Quarterly Journal of Experimental Psychology. B, Comparative and Physiological Psychology, 40, 321-341.

Slabosz, A., Lewis, S. J. G., Smigasiewicz, K., Szymura, B., Barker, R. A., \& Owen, A. M. (2006). The role of learned irrelevance in attentional set-shifting impairments in Parkinson's disease. Neuropsychology, 20, 578-588.

Strelau, J. (1983). Temperament, personality, activity. London: Academic Press.

Strelau, J. (1991). Are psychophysiological/psychophysical scores good candidates for diagnosing temperament/personality traits and for a demonstration of the construct validity of psychometrically measured traits? European Journal of Personality, 5, 323-342.

Strelau, J. (1996). The regulative theory of temperament: current status. Personality and Individual Differences, 20, 131-142.

Strelau, J., Angleitner, A., \& Bantelmann, J. (1990). The Strelau Temperament Inventory-Revised (STI-R): Theoretical considerations and scale development. European Journal of Personality, 4, 209-235.

Strelau, J., \& Klonowicz, T. (eds.). (2006). People under extreme stress. New York: Nova Science Publishers.

Strelau, J., \& Zawadzki, B. (1993). The Formal Characteristics of Behaviour-Temperament Inventory (FCB-TI): theoretical assumptions and scale construction. European Journal of Personality, 7, 313336.

Strelau, J., \& Zawadzki, B. (1995). The Formal Characteristics of Behaviour-Temperament Inventory 
(FCB-TI): Validity studies. European Journal of Personality, 9, 207-229.

Strelau, J., \& Zawadzki, B. (2005). Trauma and Temperament as Predictors of Intensity of Posttraumatic Stress Disorder Symptoms After Disaster. European Psychologist, 10, 124-135.

Strelau, J., \& Zawadzki, B. (2011). Fearfulness and anxiety in research on temperament: Temperamental traits are related to anxiety disorders. Personality and Individual Differences, 50, 907-915.

Tharp, I. J., \& Pickering, A. D. (2011). Individual differences in cognitive-flexibility: The influence of spontaneous eyeblink rate, trait psychoticism and working memory on attentional set-shifting. Brain and Cognition, 75, 119-125.

Thomas, A., \& Chess, S. (1977). Temperament and development. New York: Brunner/Mazel.

Williams-Gray, C. H., Hampshire, A., Barker, R. A., \& Owen, A. M. (2008). Attentional control in Parkinson's disease is dependent on COMT val 158 met genotype. Brain: A Journal of Neurology, 13 (Pt 2), 397-408.

Windle, M., \& Lerner, R. M. (1986). Reassessing the Dimensions of Temperamental Individuality Across the Life Span: The Revised Dimensions of Temperament Survey (DOTS-R). Journal of Adolescent Research, 1, 213-229.

Zawadzki, B., \& Popiel, A. (2012). Temperamental Traits and Severity of PTSD Symptoms: Data From Longitudinal Studies of Motor Vehicle Accident Survivors. Journal of Individual Differences, 33, 257-267.

Zawadzki, B., \& Strelau, J. (1997). Formalna charakterystyka zachowania - kwestionariusz temperamentu (FCZ-KT): podreccznik [Formal Characteristics of Behaviour - Temperament Inventory (FCB-TI): Manual]. Warszawa: Pracownia Testów Psychologicznych Polskiego Towarzystwa Psychologicznego. 